\title{
Comparison of Creativity and Self-Confidence of Gifted and Normal High School Students of District Two in Zahedan
}

\author{
Sedighe Salari ${ }^{1}$, Hossein Jenaabadi ${ }^{*}$ \\ ${ }^{1}$ Department of Psychology, Zahedan Branch, Islamic Azad University, Zahedan, Iran \\ ${ }^{2}$ Faculty of Educational Sciences and Psychology, University of Sistan and Baluchestan, Zahedan, Iran \\ Email: ${ }^{*}$ hjenaabadi@ped.usb.ac.ir
}

Received 25 May 2015; accepted 30 July 2015; published 26 October 2015

Copyright (C) 2015 by authors and Scientific Research Publishing Inc.

This work is licensed under the Creative Commons Attribution International License (CC BY).

http://creativecommons.org/licenses/by/4.0/

(c) () Open Access

\section{Abstract}

The present study aimed to compare creativity and self-confidence of gifted and normal high school students studying in district two in Zahedan. The casual-comparative method was adapted. The statistical population of the study included all male and female high school students studying in public schools, schools for exceptional talents, martyrs', non-profit and private schools in Zahedan, district two. According to the statistics, the number of male and female students studying in these schools was 8530 students, among which 368 students were selected. To collect data, Abedi Creativity Test and Moradi's Inventory of the Level of Self-Confidence (2011) were used. The obtained data were analyzed using independent t-test and MANOVA. The results of multivariate covariance analysis indicated the difference between gifted and normal students considering their creativity. Moreover, there was a significant difference between the level of self-confidence of gifted and normal high school students in Zahedan. Additionally, no significant difference was found between male and female students with regard to their creativity and self-confidence.

\section{Keywords}

Creativity, Self-Confidence, Gifted and Normal High School Students

\footnotetext{
${ }^{*}$ Corresponding author.
}

How to cite this paper: Salari, S., \& Jenaabadi, H. (2015). Comparison of Creativity and Self-Confidence of Gifted and Normal High School Students of District Two in Zahedan. Psychology, 6, 1750-1755. 


\section{Introduction}

The present study aimed to compare creativity and self-confidence of gifted and normal high school students studying in district two in Zahedan.

Gifted and talented individuals are those who indicate evidence of high performance capabilities in various areas including intellectual, creative, artistic, leadership capacity, and special academic fields. In another definition, talented and gifted students are considered those who compared to their peers are more mature and have higher developmental abilities and special levels of creativity (Mc Donald, 2004, as cited in Pfeiffer, 2008).

Previously conducted studies indicated that high intelligence and positive attributions are positively correlated with self-efficacy and flexibility. Moreover, there is a negative relationship between being gifted and some forms of mental illnesses (Herbert et al., 2004, as cited in Aghajani, Narimani, \& Ariapour, 2010). The phenomenon of intelligence is regarded as the best criterion for dividing gifted and non-gifted children (Weiner, 1997, as cited in Fahlman, 2000). Six types of capability associated with being gifted are well recognized, i.e. general intellectual ability, specific academic aptitude, creative or productive thinking, leadership ability, visual or performing art, psychomotor ability (Dixon, 1998, as cited in Fahlman, 2000). Gifted children are more independent and active and feel more comfortable when they are alone, compared to non-gifted students (Grygz, 1991, as cited in Fahlman, 2000).

For many years, behavioral specialists considered students with high intelligence as gifted students; however, in recent years, terms such as creativity and talented were used to describe gifted individuals. Accordingly, factors including intelligence, creativity, and talent are significantly critical when defining being gifted. In short, many gifted students (not necessarily all of them), compared to their peers, have higher levels of self-awareness, self-confidence, social skills, and moral responsibilities (Coleman \& Cross, 2000).

According to Weber's encyclopedia of psychology, creativity is the capacity to see new relations, establish eccentric ideas and take distance from the traditional patterns of thinking. According to Eysenck, creativity includes problem solving, forming ideas, conceptualization, making art, and theorizing which are all exquisite and unique (Haerizadeh, 2002). From the perspective of some scholars, including Baron (2003), creativity is a construct which is integrated with emotional and cognitive components (Sarvi \& Esta, 2010, as cited in Kazemi, 2011). Sternberg (1992) also stated that the concept of creativity is not single-sided and believed that multidimensional emotional and cognitive capabilities lead to creativity. Sternberg introduced creativity as thinking in an eccentric and unusual manner about issues and achieving unique methods to deal with them. Additionally, he asserted that thinking styles, knowledge, personality and environment all affect creativity (Grigorenko \& Sternberg, 1997).

Self-confidence is an aspect of self-concept which arises from one's judgments about his/her values and feelings, associated with these judgments (Sheihian, 2005). Children aged 6 to 7 years old have at least three distinct forms of self-confidence: academic, social and physical which refine more with aging. For instance, academic self-confidence is related to one's performance in various academic aspects and social self-confidence divides into the relationships with peers and parents (Burke, 2002).

Since self-esteem in children and adolescents provides the basis of their perception of life experiences, having positive self-confidence is of great importance. Social-emotional competence, which leads to a positive selfevaluation, works as a shield against future serious problems with which a child may encounter. Investigations conducted on people with low self-esteem indicated that they had reported symptoms including somatic complaints, depression, anxiety, loss of general health, apathy and loneliness or desire to attribute their failures to others, lack of job satisfaction and reduced performance, lack of educational success and having interpersonal problems (Goldenberg et al., 2001, as cited in Hadinezahd, 2008).

Pap et al. (1989) confirmed that there was a correlation between having a positive self-confidence and obtaining high scores in schools. Meftah, Baluchi and Miali Yari found that there was no significant difference between male and female students' self-confidence (As cited in Abbasi, 2008). The results of previously carried out studies on creativity indicated that there was no significant difference between male and female students considering their creativity (Ja'fari, 2008; Hajja'fari, 2006; Ghasemi and Kachlami, 2000; Naderpour, 1998). However, in a study conducted by Aligholian (1998), the results indicated that male students compared to female students were more creative. According to what was mentioned earlier, the current study aimed to compare creativity and self-confidence of gifted and normal students.

Ghobaribanab \& Hejazi (2006), in a study, examined the relationship of assertiveness and self-confidence 
with academic achievement of gifted and normal students and concluded that gifted students were better considering three variables, i.e. assertiveness, self-confidence, and academic achievement. Additionally, they demonstrated that assertiveness and self-confidence could predict students’ academic achievement.

Mohammadi (1991) conducted a study on creativity and asserted that creative people far more than other people can develop students' creative features and put a great emphasis on teachers' creativity. Isazadegan, Jenaabadi, \& Gholinejad (2013), in a study, determined the differences in thinking styles and emotional creativity between gifted and normal first grade high school students in Urmia and concluded that there was a significant difference between gifted and normal students considering their emotional creativity and thinking styles.

Bagheri, Namazian, \& Amiri (2012) conducted a study and found that spiritual intelligence was significantly correlated with creativity and achievement motivation of all students of district one in Kerman.

In a study carried out by Yadavari (2004), the effects of training social skills on general health, self-esteem, and self-assertion of first grade female high school students in Ahvaz was examined. The results demonstrated that training social skills had a positive effect on general health and its subscales, self-esteem and self-assertion and significantly increased the variables under study.

Allen (2002) conducted a study in Sweden and found that high self-esteem was directly and significantly correlated with the level of creativity and innovation of art students studying in conservatory schools in Stockholm.

Terry (as cited in Mahdavi et al., 2009), in a study, indicated that increasing self-confidence is essential for preventing the problems which may cause due to low self-esteem in adolescents.

Adams (1965) carried out a study to determine the correlation between self-esteem and creativity in students of human sciences in Pennsylvania and concluded that there was a significant relationship between self-esteem and creativity of male and female students (As cited in Mohebbi et al., 2009).

Coopersmith (1967), in a study, proved that children with high self-esteem felt talented and creative and had high levels of self-assertion and did not easily influence by environmental factors.

Objectives are as follows:

- There is a significant difference between creativity of gifted and normal high school students of district two in Zahedan.

- There is a significant difference between self-confidence of gifted and normal high school students of district two in Zahedan.

- There is a significant difference between male and female students considering their self-confidence.

- There is a significant difference between male and female students considering their creativity.

\section{Methods}

The statistical population of the study included all male and female high school students studying in public schools, schools for exceptional talents, martyrs', non-profit and private schools in Zahedan, district two. According to the statistics, the number of male and female students studying in these schools were 8530 students, among which 368 students were selected using Morgan's table. To select the sample of the current study, multi-stage random sampling method was used.

As Table 1 indicates, 50\% of students were male and 50\% of them were female.

To collect data, the following questionnaires were applied.

1) Abedi Creativity Test (CT): This test is known as CT and was developed based on Torrance theory of creativity by Abedi in Tehran in 1984. This questionnaire was revised several times and its final form with 60 items was developed in University of California by Abedi. Abedi Creativity Test (CT) has 60 3-point items and has four subscales including fluency, flexibility, originality, and elaboration. Higher scores on this questionnaire indicates having more creativity (Abedi, 1993). Each item in this questionnaire is scored from 1 to 3.1 indicates low creativity, 2 indicates moderate creativity, and 3 demonstrates high creativity. Finally, a respondent gains

Table 1. Frequency distribution and relative frequency of students’ gender.

\begin{tabular}{ccc} 
& Frequency & Percentage \\
\hline Female & 184 & 50 \\
Male & 184 & 50 \\
Total & 368 & 100.0 \\
\hline
\end{tabular}


four scores on this questionnaire's subscales and one overall score. Each respondent's score on creativity ranges from 60 to 180. In a study conducted to examine the reliability of this test, the reliability coefficients for fluency, originality, flexibility, and elaboration were $0.85,0.82,0.84$, and 0.80 , respectively (Abedi, 1993). Reliability of this test was examined using Cronbach's alpha through applying SPSS software which was higher than 0.88 .

2) Moradi's Inventory of the Level of Self-Confidence (2011): This inventory which was developed by Moradi (2011) measures the level of self-confidence. It contains 32 items which are designed based on a 5-point Likert type scale. This inventory is scored as follows Table 2.

Reliability of the questionnaire was evaluated using Cronbach's alpha through applying SPSS software which was higher than 0.85 .

\section{Results}

First Hypothesis: There is a significant difference between creativity of gifted and normal high school students of district two in Zahedan.

The results of multivariate covariance analysis demonstrated in the Table 3 indicate the difference between male and female gifted and normal high school students with regard to their creativity. According to these results, there is a significant difference between the levels of creativity of these two groups, i.e. with regard to Table 4, gifted students' levels of creativity and its components including fluency, elaboration, originality, and flexibility are higher than those of normal students and this difference is significant at the $99 \%$ confidence level.

Second Hypothesis: There is a significant difference between self-confidence of gifted and normal high school students of district two in Zahedan.

The results demonstrate that normal students' mean score on self-confidence is 90.63 and gifted students' mean

Table 2. Scoring the inventory of level of self-confidence.

\begin{tabular}{ccccc}
\hline Level of self-confidence & $\mathbf{1 2} \mathbf{- 1 6}$ years old & $\mathbf{1 7}$ - $\mathbf{2 1}$ years old & $\mathbf{2 2}-\mathbf{3 0}$ years old & More than $\mathbf{3 0}$ years old \\
\hline Very strong & $0-8$ & $0-20$ & $0-12$ & $0-10$ \\
Strong & $9-17$ & $21-36$ & $13-20$ & $16-29$ \\
Moderate strong & $18-33$ & $37-44$ & $26-40$ & $30-46$ \\
Moderate weak & $34-54$ & $45-69$ & $41-59$ & $47-66$ \\
Weak & $55-128$ & $70-128$ & $60-128$ & $67-128$ \\
\hline
\end{tabular}

Table 3. Results of multivariate covariance analysis conducted to determine the difference between gifted and normal students considering their creativity.

\begin{tabular}{|c|c|c|c|c|c|c|}
\hline Creativity groups & Students & Mean & SD & $\mathbf{F}$ & df & Sig \\
\hline \multirow{2}{*}{ Creativity } & Normal & 63.355 & 4.424 & \multirow{2}{*}{168.057} & \multirow{2}{*}{1} & \multirow{2}{*}{0.000} \\
\hline & Gifted & 65.403 & 6.449 & & & \\
\hline \multirow{2}{*}{ Fluency } & Normal & 22.842 & 6.338 & \multirow{2}{*}{58.309} & \multirow{2}{*}{1} & \multirow{2}{*}{0.000} \\
\hline & Gifted & 25.061 & 4.358 & & & \\
\hline \multirow{2}{*}{ Elaboration } & Normal & 10.345 & 1.308 & \multirow{2}{*}{48.959} & \multirow{2}{*}{1} & \multirow{2}{*}{0.000} \\
\hline & Gifted & 13.575 & 1.326 & & & \\
\hline \multirow{2}{*}{ Originality } & Normal & 17.124 & 2.382 & \multirow{2}{*}{60.201} & \multirow{2}{*}{1} & \multirow{2}{*}{0.000} \\
\hline & Gifted & 19.145 & 3.413 & & & \\
\hline \multirow{2}{*}{ Flexibility } & Normal & 10.612 & 2.345 & \multirow{2}{*}{43.486} & \multirow{2}{*}{1} & \multirow{2}{*}{0.000} \\
\hline & Gifted & 12.829 & 2.366 & & & \\
\hline
\end{tabular}

Table 4. Results of independent t-test conducted to examine the level of self-confidence of gifted and normal students.

\begin{tabular}{ccccccc}
\hline Students & N & Mean & SD & T & df & Sig \\
\hline Normal & 184 & 90.63 & 5.23 & 7.30 & 382 & 0.000 \\
Gifted & 184 & 102.28 & 6.09 & & & \\
\hline
\end{tabular}


score on self-esteem is 102.28 . Since the calculated t (7.30) with the degree of freedom of 382 is significant at the $99 \%$ confidence level, it can be concluded that there is a significant difference between levels of self-esteem of gifted and normal students of district two in Zahedan.

\section{Discussions}

First Hypothesis: There is a significant difference between creativity of gifted and normal high school students of district two in Zahedan.

To compare the mean scores of these two groups on creativity, multivariate covariance analysis (MANOVA) was used. The results of multivariate covariance analysis indicated the difference between gifted and normal students comparing their levels of creativity. According to these results, there was a significant difference between gifted and normal students' level of creativity. Gifted students obtained higher scores on creativity and its components (fluency, flexibility, originality, and elaboration) compared to normal students and this difference is significant at the 99\% confidence level. This finding is in line with the results of Halahan \& Kaufman (1992) and Isazadegan et al. (2013), indicating that gifted students compared to normal students had higher levels of creativity. Moreover, in another study, Ayson et al. showed that students studying in private schools, compared to public schools, were more creative.

To explain these results, it can be noted that due to having a sense of competition and being more enthusiastic, when gifted students spend time together, they demonstrate high levels of mental mobility. Naturally, studying in an atmosphere filled with brilliant talents creates more motivation and aids students to apply their maximum capacity of mind. Moreover, teachers' better perception of creativity can be considered as another reason for these students' higher level of creativity.

Second Hypothesis: There is a significant difference between self-confidence of gifted and normal high school students of district two in Zahedan.

The results demonstrated that normal students' mean score on self-confidence was 90.63 and gifted students' mean score on self-esteem was 102.28. Since the calculated t (7.30) with the degree of freedom of 382 was significant at the $99 \%$ confidence level, it can be concluded that there was a significant difference between levels of self-esteem of gifted and normal students of district two in Zahedan.

\section{Conclusion}

This finding is consistent with the results of Tamanaeefar (2008) and Ghobaribanab \& Hejazi (2006) who reported that gifted students, compared to normal students, had a higher level of self-confidence. Additionally, this finding is in line with the results of Dal (2000), demonstrating that gifted students' self-esteem and social skills were higher than those of normal students.

Considering the definition of self-confidence proposed by Rodgers, i.e. self-confidence is a person's continuous evaluation of his/her values and one's judgment about their values, it seems that gifted students give themselves higher scores when evaluating and judging themselves. Since these people have achieved more success in various fields, especially academic fields, compared to normal students, when evaluating themselves, they put a great emphasis on their positive points and this increases their level of self-confidence, compared to normal students. High self-confidence of gifted students reflects a positive attitude which aids students to consider their capabilities, significance, and self-value.

Creativity and innovation are the basic requirements for complex, modern, and accelerated modern human and communities. Without understanding the importance of this requirement, people have to deal with stagnation, backwardness, decline of life and slow death. Rapid changes always indicate that annihilation is waiting for you, unless you are creative and innovative (Hajidokht, 2008: p. 89). The main audiences of this warning are community leaders, policy makers, families and educational institutions that play significant crucial roles in training young generations. This helps them to choose the best appropriate way to achieve the above mentioned goal. Undoubtedly, the development of a country and its people mainly depends on paying attention to people's material and spiritual talents and capabilities. In this regard, nothing is more valuable and vital than considering creative capabilities of human resources. The transition from tradition to modernity, economic development, living standards development, establishment of democracy, cultural development, application of advanced systems are among appropriate strategies which should be considered. Talented children, adolescents, and young adults are valuable assets who can build this country; however, this will not easily take place without planning, 
investment, cultural transformation, changing attitudes, management and etc. Schools in which teachers encourage students to creativity and innovation, valuing their creativity, compared to schools which are focused on academic achievement, educate more creative students.

\section{Recommendations}

Holding workshops and conferences aiming at helping parents, teachers and other people to become familiar with methods of increasing students' creativity, putting an emphasis on the necessity of reviewing the content of educational materials and learning methods supporting students' creativity, highlighting the importance of developing creativity instead of merely academic success, planning for creating a change in teachers' attitudes towards developing creativity, planning for selecting and deploying teachers who are creative and conducting research on creativity in educational organizations are highly recommended.

1) Unwillingness of some staff to respond to the questionnaires.

2) Conservative environments in offices that may have influenced responses to the questionnaires.

3) The effect of personal biases and interests of research participants on research results.

\section{References}

Abedi, J. (1993). Creativity and New Ways of Measuring It. Psychological Research, 2, 54-46.

Aghajani, S. A., Narimani, M., \& Ariapour, S. (2010). Comparing Perfectionism and Tolerance of Ambiguity among Female Gifted and Normal Students. Iranian Journal of Exceptional Children, 11, 83-90.

Bagheri, M., Namazian, M., \& Amiri. A. (2012). The Relationship of Spiritual Intelligence with Creativity and Academic Motivation of High School Students of District One in Kerman. The National Conference of Entrepreneurship and Business Management.

Baron, R. (2003). Giftedness According the Theory of Successful Intelligence. In N. Colonel, \& G. Davis (Eds.), Handbook of Gifted Education (pp. 88-99). Boston, MA: Allyn and Bacon.

Burke, L. A. (2002). Developmental Psychology. Tehran: Arasbaran Publciation.

Coleman, L. J., \& Cross, T. L. (2000). Social-Emotional Development and the Personal Experience of Giftedness. In K. A. Heller, F. J. Monks, R. J. Stenberg, \& R. F. Subotnik (Eds.), International Handbook of Giftedness and Talent (2nd ed., pp. 203-212). Oxford: Pergamon. http://dx.doi.org/10.1016/b978-008043796-5/50015-2

Coopersmith, S. (1967). The Antecedent of Self-Esteem. San Francisco: Freeman.

Fahlman, S. (2000). Actualization of Giftedness: Effects of Perceptions in Gifted Adolescent.

Ghobaribanab, B., \& Hejazi, M. (2006). Investigating the Relationship of Assertiveness and Self-Esteem with Academic Achievement of Gifted and Normal Students. Research in the Field of Gifted Children, 7, 299-316.

Grigorenko, E. L., \& Sternberg, R. J. (1997). Styles of Thinking. Abilities and Academic Performance. Exceptional Children, 63, 295-312.

Halahan, D. P., \& Kaufman, J. (1992). Exceptional Children (Introduction to Special Education). Mashhad: Razavi Publication.

Isazadegan, A., Jenaabadi, H., \& Gholinejad, F. (2013). Comparing Thinking Styles and Emotional Creativity among Gifted and Ordinary Students. Exceptional Quarterly, 3.

Kazemi, H. (2011). Investigate the Relationship of Self-Efficacy with Creativity, Cognitive and Emotional Creativity in Students. The First National Conference on the Findings of Cognitive Science in Education, Tehran.

Sheihian, I. (2005). Self-Esteem. Tehran: Arasbaran Publication.

Yadavari, M. (2004). The Impact of Social Skills Training on Public Health, Self-Esteem, and Self-Assertion of Middle School Students in Ahvaz. MA Thesis, General Psychology, Ahvaz: Islamic Azad University. 